\title{
The cost of illness attributable to diabetic foot and cost-effectiveness of secondary prevention in Peru
}

\author{
María Kathia Cárdenas ${ }^{1}$, Andrew J. Mirelman², Cooper J. Galvin ${ }^{3}$, María Lazo-Porras ${ }^{1,4}$, Miguel Pinto ${ }^{5,6}$,
} J. Jaime Miranda ${ }^{1,6^{*}}$ and Robert H. Gilman ${ }^{1,7}$

\begin{abstract}
Background: Diabetes mellitus is a public health challenge worldwide, and roughly $25 \%$ of patients with diabetes in developing countries will develop at least one foot ulcer during their lifetime. The gravest outcome of an ulcerated foot is amputation, leading to premature death and larger economic costs.

Methods: This study aimed to estimate the economic costs of diabetic foot in high-risk patients in Peru in 2012 and to model the cost-effectiveness of a year-long preventive strategy for foot ulceration including: sub-optimal care (baseline), standard care as recommended by the International Diabetes Federation, and standard care plus daily self-monitoring of foot temperature. A decision tree model using a population prevalence-based approach was used to calculate the costs and the incremental cost-effectiveness ratio (ICER). Outcome measures were deaths and major amputations, uncertainty was tested with a one-way sensitivity analysis.
\end{abstract}

Results: The direct costs for prevention and management with sub-optimal care for high-risk diabetics is around US $\$ 74.5$ million dollars in a single year, which decreases to US $\$ 71.8$ million for standard care and increases to US\$96.8 million for standard care plus temperature monitoring. The implementation of a standard care strategy would avert 791 deaths and is cost-saving in comparison to sub-optimal care. For standard care plus temperature monitoring compared to sub-optimal care the ICER rises to US\$16,124 per death averted and averts 1,385 deaths.

Conclusion: Diabetic foot complications are highly costly and largely preventable in Peru. The implementation of a standard care strategy would lead to net savings and avert deaths over a one-year period. More intensive prevention strategies such as incorporating temperature monitoring may also be cost-effective.

Keywords: Chronic diseases, Cost analysis, Cost effectiveness analysis, Developing countries, Diabetic foot, Diabetes mellitus

\section{Background}

Diabetes mellitus is a chronic disease that presents a challenge for health care systems worldwide. One major complication of diabetes mellitus is the development of diabetic foot $[1,2]$, which may be costly for families, health systems and society. In developing countries $25 \%$ of diabetic patients develop at least one foot ulcer during their lifetime $[3,4]$ as a result of delays in diabetes

\footnotetext{
* Correspondence: Jaime.Miranda@upch.pe

${ }^{1}$ CRONICAS Centre of Excellence in Chronic Diseases, Universidad Peruana

Cayetano Heredia, Av. Armendariz 497, Lima 18, Miraflores, Peru

${ }^{6}$ Facultad de Medicina "Alberto Hurtado", Universidad Peruana Cayetano

Heredia, Lima, Peru

Full list of author information is available at the end of the article
}

diagnosis, poor access to health care and poor treatment adherence [5].

Diabetic foot is characterized by retardation and death of peripheral nervous tissue in the foot, which results in susceptibility to ulcerative infection. Over time, the gravest outcome from ulcerated feet is amputation, which may also be accompanied by pain, disability, risk of depression and decreased quality of life [3].

In 2005, the International Diabetes Federation (IDF) recommended yearly foot check-ups for all patients with diabetes in order to identify those at high-risk of ulceration [6]. In Peru, $30 \%$ of people with diabetes were unaware of 
their condition [7] and only $8 \%$ of patients undergoing treatment met control targets [7].

The objective of this analysis is to estimate the cost-ofillness (COI) attributable to diabetic foot in the patients at high-risk of ulceration in Peru for different secondary prevention strategies. A cost-effectiveness analysis is also conducted. We consider three strategies: sub-optimal care or usual care in Peru (used as comparator), standard care based on IDF recommendations, and an intensive strategy based on standard care plus temperature monitoring.

\section{Methods}

i) Design

A COI study was developed following an ingredients-based approach where unit costs for resources are multiplied by the quantity used. A decision tree model (see Fig. 1) was constructed to show cases of patients at high-risk of ulceration, diabetic foot and related outcomes. A population prevalence-based approach was performed to illustrate the costs and benefits that can be achieved in the first year of each strategy. All sources for key parameters are listed in Table 1.

ii) Definition of prevention strategies

The sub-optimal care or baseline situation was assumed to include an annual visit to a physician and podiatrist where routine tests are performed once, but neither education nor appropriate footwear is provided.

The second strategy, called standard care, was based on IDF guidelines [6], which emphasizes attention by a cadre of medical professionals, bi-monthly consultations, a higher frequency of tests, podiatrist consultation with foot evaluation, education and use of insoles (see Table 2).
Thirdly, a standard care plus temperature monitoring strategy was included, which added daily self-monitoring of foot temperature to the standard care. This involves the use of a handheld thermometer for recording and monitoring fluctuations in foot temperature of individuals. If patients find a high degree of fluctuation in temperature between both feet, higher or equal to $2.2{ }^{\circ} \mathrm{C}$, they need to call a nurse and schedule a consultation. This strategy has been applied in a number of clinical trials yielding consistent positive results [8-10].

iii) Epidemiology

Our calculations considered the Peruvian adult population (18-79 years old) with Type 2 diabetes mellitus who were at high-risk of developing diabetic foot ulcer due to severe neuropathy with foot deformity or a history of ulceration. We used the IDF national data for the prevalence of Type 2 diabetes in Peru, estimated at $5.38 \%$ in year 2011 [11]. This resulted in nearly 942,000 people having the disease. The prevalence of being at high-risk for diabetic foot was defined as the prevalence rate of severe neuropathy among diabetic patients, assumed to be $21.9 \%$ based on previous studies for developing countries $[12,13]$. It was calculated that the population in Peru with severe neuropathy was 206,298 persons. We have excluded patients with peripheral ischemia from our approach given that this population was also excluded in clinical trial studies exploring temperature monitoring as a preventative strategy for diabetic foot [8-10].

The three different prevention strategies affected a reduction in the one-year ulceration rate for those that were at high-risk for diabetic foot. To illustrate

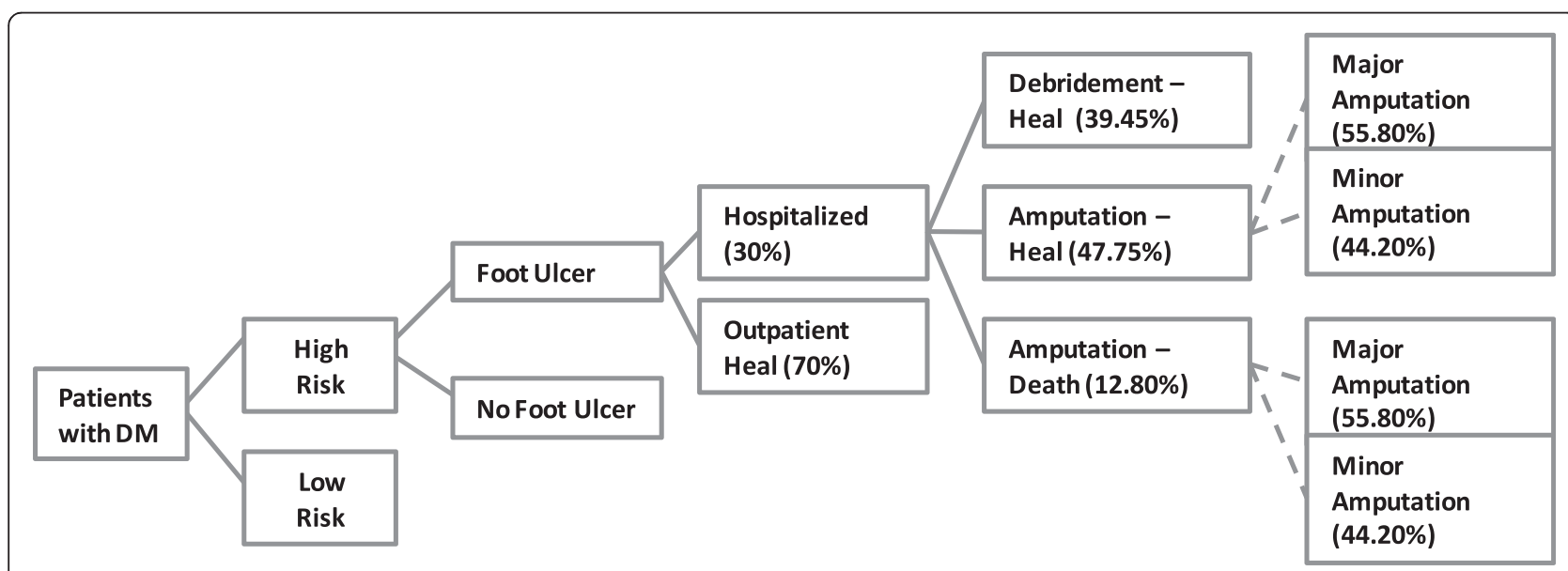

Fig. 1 Decision tree diagram for patients at high-risk of ulceration, diabetic foot and related outcomes 
Table 1 Epidemiology and cost inputs

\begin{tabular}{|c|c|c|c|c|}
\hline Parameter & Value & Lower estimate & Upper estimate & Reference \\
\hline \multicolumn{5}{|l|}{ Epidemiology } \\
\hline $\begin{array}{l}\text { a. Total population with Type } 2 \text { diabetes } \\
\text { mellitus }\end{array}$ & 942,000 & & & {$[11]$} \\
\hline b. \% diabetics at high risk for ulcer & $21.90 \%$ & & & {$[12,13]$} \\
\hline c. Prevalence of ulcer in those at high-risk & $22.18 \%$ & $15.53 \%$ & $28.84 \%$ & $\begin{array}{l}{[9,14,15] \text { Own assumption: values for lower }} \\
\text { and upper estimate }+/-30 \%\end{array}$ \\
\hline $\begin{array}{l}\text { c1. Effectiveness (reduced prevalence) with } \\
\text { standard care }\end{array}$ & $45.00 \%$ & $30.00 \%$ & $60.00 \%$ & $\begin{array}{l}{[9,14,15] \text { Own assumption: assumed values }} \\
\text { for lower and upper estimate. }\end{array}$ \\
\hline $\begin{array}{l}\text { C2. Effectiveness (reduced prevalence) with } \\
\text { standard care plus temperature } \\
\text { monitoring }\end{array}$ & $78.81 \%$ & $65.00 \%$ & $85.00 \%$ & $\begin{array}{l}{[9,14,15] \text { Own assumption: assumed values }} \\
\text { for lower and upper estimate. }\end{array}$ \\
\hline d. \% with ulcer receiving hospital care & $30.00 \%$ & $21.00 \%$ & $39.00 \%$ & $\begin{array}{l}\text { [16] Own assumption: values for lower and } \\
\text { upper estimate }+/-30 \%\end{array}$ \\
\hline $\begin{array}{l}\text { e. \% with ulcer receiving outpatient wound } \\
\text { management }\end{array}$ & $70.00 \%$ & $61.00 \%$ & $79.00 \%$ & $\begin{array}{l}\text { [16] Own assumption: values for lower and } \\
\text { upper estimate. }\end{array}$ \\
\hline f. \% at hospital with amputation and heal & $47.75 \%$ & $33.43 \%$ & $62.08 \%$ & $\begin{array}{l}\text { [16] Own assumption: values for lower and } \\
\text { upper estimate }+/-30 \%\end{array}$ \\
\hline f1. \% with major amputation & $55.80 \%$ & & & {$[16]$} \\
\hline f2. \% with minor amputation & $44.20 \%$ & & & [16] \\
\hline g. $\%$ at hospital with debridement and heal & $39.45 \%$ & $25.12 \%$ & $53.77 \%$ & $\begin{array}{l}\text { [16] Own assumption: values for lower and } \\
\text { upper estimate }+/-30 \%\end{array}$ \\
\hline $\begin{array}{l}\text { h. \% at hospital that die of diabetic foot } \\
\text { after an amputation }\end{array}$ & $12.80 \%$ & & & {$[16]$} \\
\hline \multicolumn{5}{|l|}{ Direct costs (in 2012 US dollars) } \\
\hline \multicolumn{5}{|l|}{ Prevention } \\
\hline Sub-optimal care & 65 & 45 & 84 & $\begin{array}{l}{[17,18] \text { Other local prices. Own assumption: }} \\
\text { values for lower and upper estimate } \\
+/-30 \%\end{array}$ \\
\hline Standard care & 185 & 129 & 240 & $\begin{array}{l}{[17,18] \text { Other local prices. Own assumption: }} \\
\text { values for lower and upper estimate } \\
+/-30 \%\end{array}$ \\
\hline Standard care plus temperature monitoring & 406 & 285 & 528 & $\begin{array}{l}{[17,18] \text { Other local prices. Own assumption: }} \\
\text { values for lower and upper estimate } \\
+/-30 \%\end{array}$ \\
\hline \multicolumn{5}{|l|}{ Treatment } \\
\hline $\begin{array}{l}\text { Wound management without } \\
\text { hospitalization }\end{array}$ & 79 & & & {$[17,18]$ Other local prices. } \\
\hline Debridement & 1,022 & & & {$[17,18]$ Other local prices. } \\
\hline Minor amputation & 5,153 & & & {$[17,18]$ Other local prices. } \\
\hline Major amputation & 7,360 & 5,152 & 9,568 & $\begin{array}{l}{[17,18] \text { Other local prices. Own assumption: }} \\
\text { values for lower and upper estimate } \\
+/-30 \%\end{array}$ \\
\hline \multicolumn{5}{|l|}{ Indirect costs (in 2012 US dollars) } \\
\hline Productivity loss from premature death & 6,719 & & & $\begin{array}{l}\text { Peru's basic salary in year 2012; } 3 \% \\
\text { discount rate. }\end{array}$ \\
\hline
\end{tabular}

the achievable health benefits, it was assumed that each strategy was introduced at scale. For the sub-optimal care strategy as baseline, the ulceration prevalence rate was assumed to be $22.18 \%$. This figure came from considering the ulceration prevalence rate for the standard care in a clinical trial study reported as $12.2 \%$ [9], together with an effectiveness estimations of $45 \%$ derived from the United States Center for Disease Control and Prevention (CDC) $[14,15]$ when moving from a 
Table 2 Major assumptions in cost-of-illness estimation

A. Wound management without hospitalization

Outpatient: 1 first visit, 2 visits of control, 3 minor healing procedures in a hospital. Test: HbA1C, lipid profile, X-ray. Medication: Clindamycin $300 \mathrm{mg}$ gid for 2 weeks.

\section{B. Debridement}

Inpatient: Emergency consultation, 6 days of hospitalization, evaluation by anesthesiologist and cardiologist, anesthesiology medication and surgical materials, debridement procedure, intermediate care unit and 6 wound healing procedures. Test: Pre-surgery tests, antibiogram, $\mathrm{HbA1C}$, lipid profile and X-ray. Medication: Intravenous antibiotic (Ampicillin/ Sulbactam $1.5 \mathrm{~g}$ qid for 3 days), oral antibiotics for 11 days and peripheral line. Outpatient: Consultations with physician until healed at the hospital and materials for dressing changes.

\section{Amputation}

Inpatient: Emergency consultation, 10 days (minor amputation) or 19 days (major amputation) of hospitalization, evaluation by anesthesiologist and cardiologist, anesthesiology medication and surgical materials, amputation procedure, intermediate care unit and blood transfusion. Test: Pre-surgery tests, bacteriology study, HbA1C, lipid profile, white cells count, X-ray, Doppler echography, arteriography, MRl, tissue biopsy. Medication: Intravenous antibiotic (Ampicillin/Sulbactam $1.5 \mathrm{~g}$ qid for 3 days in minor amputation and 5 days in major amputation), oral antibiotics (11 days in minor and 16 days in major amputation) and peripheral line. Outpatient: Consultations with physician and podiatrist until healed, materials for dressing changes (assuming that a nurse or a trained person at home is in charge of this procedure). Others: Rehabilitation sessions (40 for minor amputation and 50 for major amputation), orthopedic supplies for foot amputation (crutches and orthopedic foot) or for leg amputation (crutches, orthopedic leg, wheelchair), caregiver at home (conservative assumption of 6 months at Peru's basic salary or 12 months working partial time).

\section{Premature death}

We assumed that 2 years (retirement age of 65) of paid productive work were lost due to the death and discounted at an annual rate of $3 \%$. Minimum wage rate in Peru amounts to PEN 750 in year 2012 (equivalent to US\$284). We assumed a monthly income equal to minimum wage. The estimated indirect cost was US\$6,719, which is the net value of the lost earnings for the next 2 years.

E. Sub-optimal care

Outpatient: 1 annual consultation with physician and podiatrist. Test: 1 annual testing of $\mathrm{HbA1C}$, lipid profile, creatinine, electrocardiogram, X-ray.

F. Standard care

Outpatient: 6 consultations with physicians, 1 consultation with the podiatrist and 1 education session with a nurse. Test: 3 annual evaluations of $\mathrm{HbA} 1 \mathrm{C}, 1$ annual testing of lipid profile, 2 creatinine tests, 2 electrodiagrams and $1 \mathrm{X}$-ray. Others: protective footwear (a pair).

G. Standard care plus temperature monitoring

Similar to standard care, but in addition: thermometer and daily phone calls assisted by a nurse or a trained person (about 5 minutes per patient everyday).

HbA1C glycosylated hemoglobin, MRI magnetic resonance imaging

scenario of sub-optimal care to standard care. An even higher reduction of $79 \%$ in the baseline rate of ulceration is achieved with the standard care plus temperature monitoring, achieving a $4.7 \%$ of ulceration rate [9].

iv) Clinical outcomes

We determined the likely clinical outcomes for different scenarios. The data was for a one-year period related to diabetic foot treatment and complications such as ulcer development, wound management, debridement procedure, amputation and death. We considered the parameters from a Brazilian study [16] that provides rates for hospitalization and outcomes attributed to diabetic foot ulceration in patients attended by the public health system. This kind of study has not been implemented in Peru and there is a lack of reliable epidemiological data from the health statistics at hospitals. In the Brazilian COI study [16], $70 \%$ of ulcerated patients heal without hospitalization, and therefore, we assumed that those patients only receive outpatient wound management. The other $30 \%$ of patients require hospitalization, with $39.5 \%$ healing with primary care (assumed as debridement procedure), $47.8 \%$ healing by a minor or major amputation, and $12.8 \%$ dying after amputation surgery. Our assumption here is that all patients who die had an amputation in the same year. Among those patients who undertook amputation surgery in the Brazilian study, $44.2 \%$ received a minor amputation and $55.8 \%$ a major amputation. Table 1 shows the values used and assumptions made for this study.

v) Cost data

Direct costs of resources used to prevent or manage the disease were registered under a societal perspective. We identified the main medical procedures that can be carried out in Peru related to each stage of diabetic foot. We followed an ingredients-based approach for our costing analysis (see Additional file 1). We estimated the number of specific procedures, personnel, medical supplies, examinations and medications for each disease stage according to the IDF guidelines. The unit costs of treatment were taken from a list of tariffs in a public hospital of the Ministry of Health in Peru [17]. We considered generic drug prices [18]. Costs were registered at the local currency Peruvian Nuevos Soles (PEN) and converted to US dollars (US\$), considering an average exchange rate of 2.64 PEN per dollar in year 2012 [19]. Additionally, the indirect costs due to premature death were measured using a human capital approach. Minimum wage rate in Peru amounts to US\$284 in year 2012. We assumed a monthly income equal to minimum wage and a mean age of 63 years for premature mortality, according to the primary data of patients with neuropathy in a public hospital in Lima [12]. We considered that two years, with a retirement age of 65 , of paid productive work were lost due to the death and discounted at an annual rate of $3 \%$. 
vi) Cost-effectiveness analysis

Cost-effectiveness is examined in terms of cost per deaths averted. The analysis consisted in estimating the incremental cost-effectiveness ratio (ICER) by estimating the additional costs and deaths averted for each of the preventive strategies compared to the sub-optimal strategy. Since the analysis only looked at costs and effects for one-year, there was no discounting.

vii) Sensitivity analysis

We conducted multiple one-way sensitivity analysis to assess the uncertainty of the key input parameters. The variables of interest were independently varied according to their plausible range from Table 1. Most of the variables were varied using a range of $+/-30 \%$, given that uncertainty ranges were not available in the literature. The resulting change in cost-effectiveness was then taken and the variables were ordered in a tornado diagram from the most to the least sensitive parameter.

viii) Key assumptions

The model assumed that healthcare utilization is $100 \%$ and constant for the entire population. Finally, our approach does not discriminate by rural-urban setting, assuming that all patients attend urban hospitals.

\section{Ethics}

We did not submit this study for ethics committee review as no human subjects were involved in this research study. We used aggregated and de-identified secondary information from public domain sources.

\section{Results}

Direct costs of prevention and treatment of diabetic foot ulcer in year 2012 varied depending on the different strategies (see Table 3 ). The total COI, using only direct costs for the three strategies adding preventive and treatment costs was US $\$ 74,470,803$ for sub-optimal care, US $\$ 71,745,988$ for standard care and US\$96,800,267 for standard care plus temperature monitoring. Standard care strategy generates savings of roughly US\$2.7 million compared to sub-optimal care. Switching to the standard care plus temperature monitoring strategy adds additional cost to the sub-optimal strategy of approximately US\$22 million.

Figure 2 shows the COI results by category of resources used. For sub-optimal and standard care, the major cost drivers are inpatient visits, outpatient visits, laboratory tests and other supplies. With standard care plus temperature monitoring, these costs are greatly reduced due to a larger reduction in the number of ulcerations, but the high cost of the thermometer device plays a significant role.

Table 4 provides the total outcomes averted and costeffectiveness estimates for the strategies. In the baseline sub-optimal strategy, our model gives that there will be 1,757 deaths resulting from foot ulceration (using a $22.18 \%$ prevalence rate). The standard care will avert 791 of these deaths (using a $12.2 \%$ prevalence rate) and the standard

Table 3 Cost of illness (direct costs) attributed to diabetic foot (2012 US dollars)

\begin{tabular}{|c|c|c|c|c|c|c|c|}
\hline \multirow{2}{*}{$\begin{array}{l}\text { Description } \\
\text { Prevention strategy }\end{array}$} & \multirow[t]{2}{*}{ All strategies } & \multicolumn{2}{|c|}{ Sub-optimal care } & \multicolumn{2}{|l|}{ Standard care } & \multicolumn{2}{|c|}{$\begin{array}{l}\text { Standard care plus temperature } \\
\text { monitoring }\end{array}$} \\
\hline & & & & & & & \\
\hline Cost per person & & & US\$65 & & US\$185 & & US\$406 \\
\hline Total people & & & 206,298 & & 206,298 & & 206,298 \\
\hline Total cost of prevention & & & US $\$ 13,350,763$ & & US\$38,129,966 & & US $\$ 83,849,832$ \\
\hline Complications & Cost/person & No. of people & Total cost & No. of people & Total cost & No. of people & Total cost \\
\hline \multicolumn{8}{|l|}{ Hospital } \\
\hline Healing with debridement & US\$1,022 & 5416 & US\$5,535, 166 & 2979 & US $\$ 3,044,341$ & 1148 & US\$1,172,820 \\
\hline Healing with major amputation & US\$7,360 & 3658 & US $\$ 26,921,264$ & 2012 & US $\$ 14,806,695$ & 775 & US $\$ 5,704,219$ \\
\hline Healing with minor amputation & US $\$ 5,153$ & 2897 & US $\$ 14,930,136$ & 1594 & US\$8,211,575 & 614 & US $\$ 3,163,476$ \\
\hline Death with major amputation & US\$7,360 & 981 & US\$7,216,590 & 539 & US\$3,969,125 & 208 & US\$1,529,089 \\
\hline Death with minor amputation & US $\$ 5,153$ & 777 & US\$4,002,215 & 427 & US\$2,201,218 & 165 & US\$848,010 \\
\hline Subtotal & US\$26,048 & 13728 & US\$58,605,371 & 7551 & US\$32,232,954 & 2909 & US\$12,417,613 \\
\hline \multicolumn{8}{|l|}{ Outpatient } \\
\hline Healing with outpatient visit & US\$79 & 32032 & US\$2,514,669 & 17618 & US\$1,383,068 & 6787 & US\$532,821 \\
\hline $\begin{array}{l}\text { Total No. of people/Total cost } \\
\text { of treatment }\end{array}$ & & 45761 & US $\$ 61,120,040$ & 25168 & US $\$ 33,616,022$ & 9696 & US\$12,950,435 \\
\hline Total cost & & & US $\$ 74,470,803$ & & US $\$ 71,745,988$ & & US\$96,800,267 \\
\hline
\end{tabular}




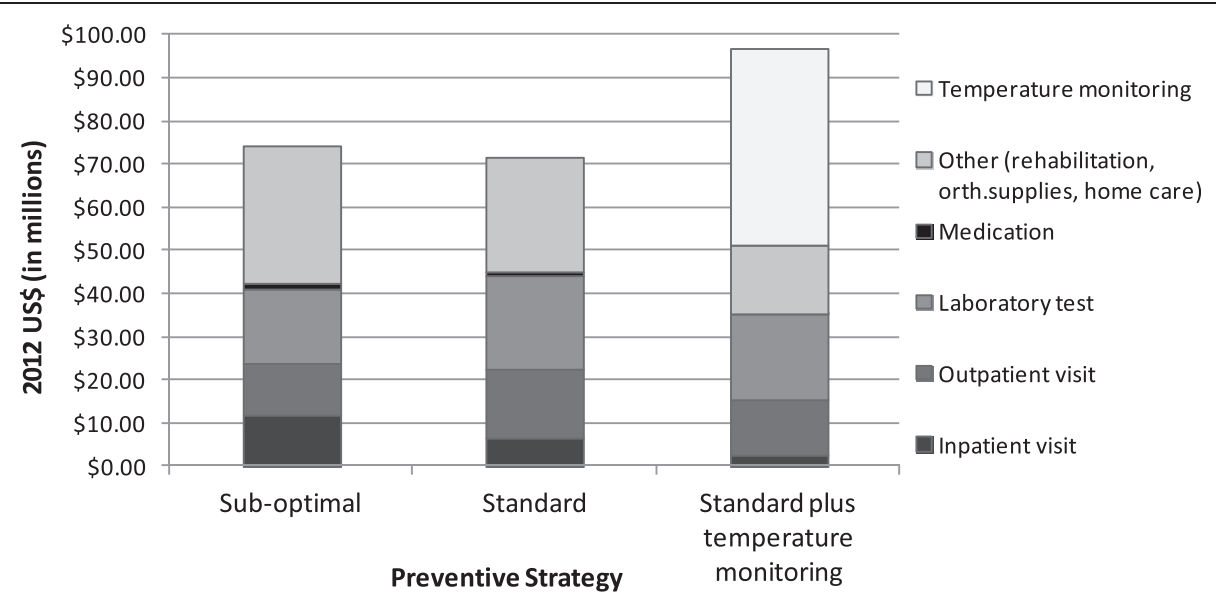

Fig. 2 Resource usage for treatment and prevention of diabetic foot and related complications

care plus temperature monitoring strategy will avert 1,385 of the total deaths (using a $4.7 \%$ prevalence rate). In terms of the health system burden, the standard care strategy will avert 2,087 major amputations compared to the suboptimal care strategy, and standard care plus temperature monitoring will prevent 3,656 major amputations compared to the sub-optimal care strategy (see Table 4).

The ICER for standard care versus the sub-optimal care is negative because of the cost-savings and is thus a highly favored outcome. The ICER for standard care plus temperature monitoring versus sub-optimal care indicates that US\$16,124 dollars need to be spent for each additional death averted. The estimated indirect cost was US\$6,719, which is the net value of the lost earnings for the next two years. When adding the indirect costs, the ICER for standard care plus temperature monitoring versus sub-optimal care becomes even more favorable, at US\$9,405 per death averted. When comparing standard care plus temperature monitoring versus standard care, the ICER is over US $\$ 35,000$ per death averted.
At the current baseline estimate, the ICERs are either cost-saving or around US $\$ 16,000$ per death averted for standard care and standard care plus temperature monitoring compared to sub-optimal care. Figure $3 \mathrm{a}$ and $\mathrm{b}$ show the results of a deterministic sensitivity analysis for these findings. The most sensitive variable in each case is the cost of the preventative strategy, which at a higher value, makes the ICER of standard care and standard care plus temperature monitoring less favorable. For the standard care option, the effectiveness of ulcer reduction by standard care, baseline ulcer prevalence and hospital utilization are the next most important variables. For standard care plus temperature monitoring, the second and third most sensitive parameters are baseline ulcer prevalence and hospital utilization, while the effectiveness of ulcer reduction was the fourth most sensitive variable.

\section{Discussion}

Main findings

Diabetic foot prevention and management certainly result in high economic burden for the Peruvian health system

Table 4 Outcomes and cost-effectiveness of secondary prevention for diabetic foot

\begin{tabular}{llll}
\hline Comparison & $\begin{array}{l}\text { Standard care vs. } \\
\text { sub-optimal care }\end{array}$ & $\begin{array}{l}\text { Standard care plus temperature } \\
\text { monitoring vs. sub-optimal care }\end{array}$ & $\begin{array}{l}\text { Standard care plus temperature } \\
\text { monitoring vs. Standard care }\end{array}$ \\
\hline Differences in costs $(\Delta$ costs) & US $\$ 2,724,815$ & US $\$ 22,329,464$ & US $\$ 25,054,279$ \\
Direct costs & - US $\$ 8,037,824$ & US $\$ 13,024,440$ & US $\$ 21,062,264$ \\
Direct costs + Indirect costs & 791 & 1,385 & 594 \\
Differences in deaths ( $\Delta$ deaths) & 2,087 & 3,656 & 1,568 \\
Differences in major amputations & & & ICER $=42,169$ \\
$\begin{array}{l}\text { Incremental cost-effectiveness ratio } \\
(\Delta \text { costs } \Delta \text { deaths) }\end{array}$ & Cost-saving & ICER $=16,124$ & ICER $=35,450$ \\
Direct costs & Cost-saving & ICER $=9,405$ & \\
Direct costs + Indirect costs & & &
\end{tabular}




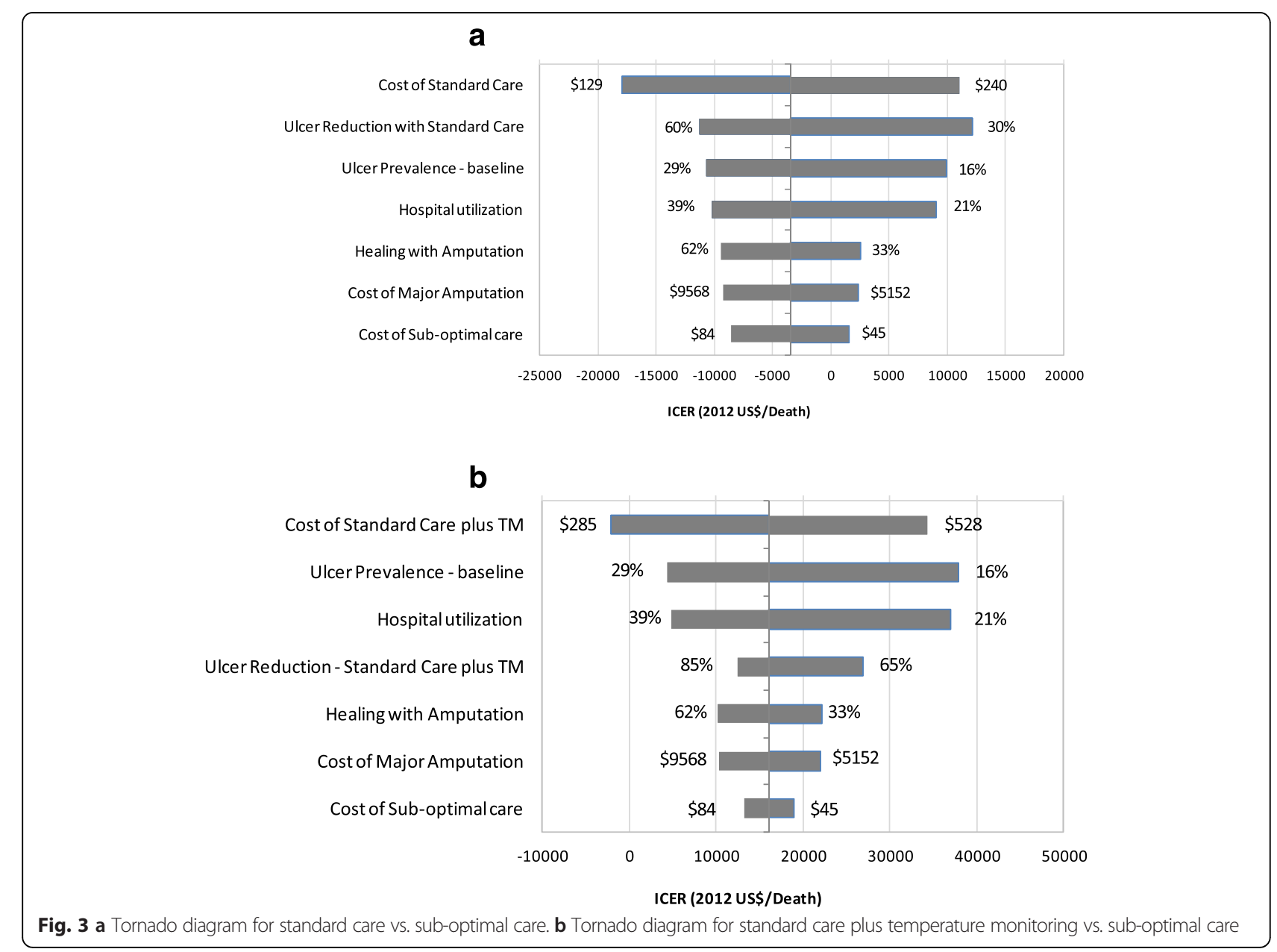

and society as well. The overall COI for prevention and complications management with standard care strategy would amount to a total savings of roughly US $\$ 2.7$ million and avert 791 deaths. Our findings suggest that secondary prevention strategies are cost-effective for the individuals and the government of Peru if properly implemented. We note that ICER values per disability adjusted life year (DALY) are usually compared with three times the Gross Domestic Product (GDP) per capita of a country, which for Peru was US\$6,568 in 2012 [20]. Our ICER using deaths averted is potentially more conservative given that disability benefits are not accounted for. ICER fell under three times the GDP per capita (US\$16,124), we are confident it would be considered cost-effective [21].

Furthermore, standard care alone is even cost-saving, i.e. total costs decrease and deaths averted increase in comparison to sub-optimal care. When adding the indirect costs of lost productivity, the ICER for standard care versus sub-optimal care remains cost-saving and the standard care plus temperature monitoring versus suboptimal care becomes more favorable, at US $\$ 9,405$ per death averted. The sensitivity analysis showed that for the standard care only, the ICERs still fell under three times the GDP after varying the key parameters by $+/-30 \%$.

From this analysis, a preventative strategy such as standard care not only improves the current level of care, but also leads to economic benefits in terms of societal cost-savings. Since prevention must be provided to a large number of patients at high-risk of ulceration, total costs of the prevention strategies are high; however, in the case of standard care plus temperature monitoring, the costs of thermometers would decline over time after the initial investment. For this strategy, even if the cost of the thermometer was zero, the strategy of standard care plus temperature monitoring would be cost-effective but not cost-saving. In the future, temperature monitoring technology may be integrated with electronic and mobile health prevention platforms that could further reduce the costs of personnel and phone services and make the intervention even more attractive.

\section{Comparison with the literature}

Direct annual costs per patient calculated for management of foot ulcers and other diabetic foot complications are 
lower in Peru than costs estimated in other studies for developed countries [22-25]. Ulcers that require amputation can cost, per admission, from US $\$ 15,790[26,27]$ to as high as US $\$ 45,870[23,27]$. In contrast, a study in Brazil [16] used a hypothetical cohort including all the Brazilian citizens with Type 2 diabetes and estimated a total annual cost of hospital admissions per patient starting from US\$2,151.

The reported costs of diabetic foot prevention and treatment in developing and developed nations are difficult to compare, further emphasizing the importance of studies such as ours. Previous studies in cost-effective interventions to prevent and control diabetes agree with our estimates that comprehensive and multidisciplinary foot care leads to cost-savings [28-33]. One systematic review [28] included two studies that dealt with diabetic foot prevention, and one of these studies used an optimal care strategy similar to our standard care strategy [32]. An intensive prevention strategy including patient education, foot care and footwear was found to be cost-saving if the risk for foot ulcers and lower extremity amputations were reduced by $25 \%$ [32] among those patients at risk of ulceration. In our study we assumed a reduction of ulceration rate of $45 \%$ in line with lower bound estimates shown by the Centers for Disease Control and Prevention for potential reductions in amputation as a result of comprehensive foot care program [14, 15]. A retrospective cohort study from Austria using a Markov model, compared a dedicated screening program with conventional preventive care and concluded that the screening program would reduce costs by $29.8 \%$ for mild ulcers and by $49.7 \%$ for severe ulcers, primarily due to lower amputation rates [34]. Ollendorf et al. [35] estimated an increasing economic benefit associated to educational interventions, multidisciplinary teams, and the therapeutic shoe coverage. They did not, however, include the costs of the underlying intervention strategies.

Recent published studies indicate that the use of temperature monitoring is an effective way to prevent diabetic foot ulceration; however the cost-effectiveness of temperature monitoring had not been yet studied $[29,30]$. Our study provides relevant findings about the potential of standard care plus temperature monitoring as a cost-effective prevention strategy even in a shortterm horizon. However, standard care as recommended by the IDF is still more cost-effective and provides net savings for the society.

\section{Limitations}

This study was performed from a societal perspective considering all direct healthcare costs, regardless of who paid; however, we did not include more assumptions about travel costs and waiting time given the lack of reliable information for those estimates. In this study, we tried to be as conservative as possible when considering the most appropriate health outcome indicator or whether to include indirect costs into the analysis. We have only considered productivity losses as indirect cost calculated under the "human capital" approach. This approach generates large estimates, but we presented our results of the ICER both including and excluding the productivity costs. For the purpose of this cost-effectiveness study, we chose two tangible outcomes as health effect indicators: amputations and deaths. Further cost-utility analysis may extend this to looking at a summary health outcome that incorporates morbidity such as the quality adjusted life year (QALY) or DALY. The estimates in this study are also limited by the lack of available data on clinical outcomes of preventative strategies specific to diabetic foot in Peru. As a result, we at times used secondary information from other country settings while aiming to use data from developing countries.

Another limitation is the model assumption that healthcare utilization was $100 \%$ and constant for the entire population. We considered this assumption given the severe condition of these kinds of patients and given the lack of information on this issue. However, we expect that a lower utilization rate would lead to more major complications and more fatal outcomes of those who do not receive timely medical care.

We also assume that the parameters apply for the whole country and do not make a distinction between rural and urban populations. It is likely that this decision contributes to an underestimation of the total COI because the rural population will most likely incur larger indirect costs due to travel and time to reach a hospital in urban area. Our study calculated an ulcer rate using the data from a clinical study that occurred over an 18-month period [9], because longitudinal data is not yet available.

We only investigated the secondary prevention methods for diabetic foot, and given the lack of data for the burden of Type 1 diabetes, we did not include a comprehensive overhaul of diabetes monitoring and prevention in order to not overestimate and attribute costs that are also related with other complications (retinopathy, kidney diseases, among others). We chose to provide a detailed breakdown of costs, yearly costs, and unit costs, each presented separately. To ensure the wide applicability of our study, we have offered a breakdown of the likely routes for resource allocation in a given year. We are aware that there are intangible benefits for the patients and their families that are impossible to measure in monetary terms. We also only looked at the economic burden of the disease for the first year assuming that each prevention strategy achieved full scale-up.

While aiming to produce a conservative estimate of the cost of ulceration and amputation, we left out the added risk for recurrent ulcers and new amputations, which could 
be included in the future development of a probabilistic Markov model.

\section{Implications and further research}

Diabetes prevalence in Peru is rising [36] and there is a low level of disease awareness and control [7]. Thus monitoring and treatment protocols are urgently needed. The health and economic impacts of diabetic foot are exacerbated in Peru because of insufficient preventative measures. We recommend validating costs and collecting better epidemiological data for diabetic foot disease in Peru.

\section{Conclusion}

We have provided an economic evaluation for tracing costs related to prevention methods of diabetic foot disease in a developing country. Our study found a costsaving result and decreased mortality associated with adherence to the standard care as recommended by the IDF relative to the current sub-optimal care that is provided in Peru. Additionally, we found that standard care plus temperature monitoring was a promising costeffective strategy and could be even more cost-effective with declining price in the thermometer device. Our results highlight the important economic impact on savings and lives saved that diabetic foot programs can yield.

\section{Additional file}

Additional file 1: Cost estimates of procedures and preventative strategies using the ingredients-based approach (Peru, 2012). (XLS $57 \mathrm{~kb}$ )

\section{Abbreviations}

COI: Cost-of-illness; GDP: Gross domestic product; ICER: Incremental cost-effectiveness ratio; IDF: International Diabetes Federation; PEN: Peruvian Nuevos Soles.

\section{Competing interests}

The authors declare that they have no competing interests.

\section{Authors' contributions}

Conceived the project: MKC, CJG, JJM, RHG. Gathered data: CJG, MKC, MLP. Data analysis and interpretation: MKC, AJM. Provided medical clinical insight: MLP, JJM, MP, RHG. Drafted an initial version of the manuscript: MKC, CJG. Provided critical input to earlier versions of the manuscript: JJM, RHG. All authors revised and approved the final version.

\section{Acknowledgements \\ The study was partially funded by the National Heart, Lung And Blood Institute, National Institutes of Health, Department of Health and Human Services (contract number HHSN268200900033C) through support to core and training-related activities of the CRONICAS Centre of Excellence in Chronic Diseases at Universidad Peruana Cayetano Heredia. The study sponsor had no role in study design; in the collection, analysis, and interpretation of data; in the writing of the report; and in the decision to submit the paper for publication.}

\section{Author details}

${ }^{1}$ CRONICAS Centre of Excellence in Chronic Diseases, Universidad Peruana Cayetano Heredia, Av. Armendariz 497, Lima 18, Miraflores, Peru. ${ }^{2}$ Centre for Health Economics, University of York, York, UK. ${ }^{3}$ Stanford University, Stanford, CA, USA. ${ }^{4}$ Unidad de Conocimiento y Evidencia, Universidad Peruana
Cayetano Heredia, Lima, Peru. ${ }^{5}$ Servicio de Endocrinología, Hospital Nacional Cayetano Heredia, Lima, Peru. ${ }^{6}$ Facultad de Medicina "Alberto Hurtado", Universidad Peruana Cayetano Heredia, Lima, Peru. 'Department of International Health, Johns Hopkins Bloomberg School of Public Health, Baltimore, MD, USA.

Received: 5 September 2014 Accepted: 12 October 2015

Published online: 26 October 2015

\section{References}

1. Melmed S, Polonsky KS, Larsen PR, Kronenberg HM. Williams textbook of endocrinology. 12th ed. Philadelphia: Elsevier/Saunders; 2011. p. 1371-435.

2. Frykberg RG, Zgonis T, Armstrong DG, Driver VR, Giurini JM, Kravitz SR, et al. Diabetic foot disorders: a clinical practice guideline (2006 revision). J Foot Ankle Surg. 2000:45(5 Suppl):S1-S66.

3. Kerr M. Foot Care for People with Diabetes: The Economic Case for Change. NHS Diabetes 2012. http://www.diabetes.org.uk/Documents/nhs-diabetes/ footcare/footcare-for-people-with-diabetes.pdf. Accessed 10 Aug 2013.

4. Boulton AJ, Vileikyte L, Ragnarson-Tennvall G, Apelqvist J. The global burden of diabetic foot disease. Lancet. 2005:366(9498):1719-24.

5. Singh N, Armstrong DG, Lipsky BA. Preventing foot ulcers in patients with diabetes. JAMA. 2005:293(2):217-28.

6. International Diabetes Federation. Clinical Guidelines Task Force. Global Guideline for Type II Diabetes. Brussels: International Diabetes Federation; 2005.

7. Lerner AG, Bernabe-Ortiz A, Gilman RH, Smeeth L, Miranda JJ. The "rule of halves" does not apply in Peru: awareness, treatment, and control of hypertension and diabetes in rural, urban, and rural-to-urban migrants. Crit Pathw Cardiol. 2013;12(2):53-8.

8. Lavery LA, Higgins KR, Lanctot DR, Constantinides GP, Zamorano RG, Athanasiou KA, et al. Preventing diabetic foot ulcer recurrence in high-risk patients: use of temperature monitoring as a self-assessment tool. Diabetes Care. 2007;30(1):14-20.

9. Armstrong DG, Holtz-Neiderer K, Wendel C, Mohler MJ, Kimbriel HR, Lavery L. Skin temperature monitoring reduces the risk for diabetic foot ulceration in high-risk patients. Am J Med. 2007;120(12):1042-6.

10. Lavery LA, Higgins KR, Lanctot DR, Constantinides GP, Zamorano RG, Armstrong DG, et al. Home monitoring of foot skin temperatures to prevent ulceration. Diabetes Care. 2004;27(11):2642-7.

11. Whiting DR, Guariguata L, Weil C, Shaw J. IDF diabetes atlas: global estimates of the prevalence of diabetes for 2011 and 2030. Diabetes Res Clin Pract. 2011;94(3):311-21.

12. Gamarra MA. Características clínicas y factores de riesgo para pie diabético en los pacientes que acuden a la unidad de pie diabético del "Hospital Nacional Dos de Mayo" [Clinical characteristics and risk factors for diabetic foot patients attending the diabetic foot unit from "Hospital Nacional Dos de Mayo"]. Postgraduate Thesis - Specialist in Endocrinology. 2003. http://sisbib.unmsm.edu.pe/bibvirtual/monografias/salud/gamarra_cm/ contenido.htm. Accessed 10 Aug 2013.

13. Herman W, Aubert R, Eneroth M, Thompson T, Ali M, Sous E, et al. Diabetes Mellitus in Egypt: Glycaemic Control and Microvascular and Neuropathic Complications. Diabet Med. 1998;15(12):1045-51.

14. Centers for Disease Control and Prevention. National Diabetes Fact Sheet. 2011. http://www.cdc.gov/diabetes/pubs/pdf/ndfs_2011.pdf. Accessed 11 Aug 2013.

15. Bild DE, Selby JV, Sinnock P, Browner WS, Braveman P, Showstack JA. Lower-extremity amputation in people with diabetes. Epidemiology and prevention. Diabetes Care. 1989;12(1):24-31.

16. Rezende KF, Ferraz MB, Malerbi DA, Melo NH, Nunes MP, Pedrosa HC, et al. Predicted annual costs for inpatients with diabetes and foot ulcers in a developing country-a simulation of the current situation in Brazil. Diabet Med. 2010;27(1):109-12.

17. Ministry of Health. Catálogo Tarifario de Servicios de Salud del Hospital Nacional Hipólito Unanue [Pricing of Healthcare Services at the Public Hospital "Hipólito Unanue"]. 2009. http://www.hnhu.gob.pe/CUERPO/ TARIFARIO/TARIFARIO\%202009.pdf. Accessed 10 Aug 2013.

18. Ministry of Health. Observatorio Peruano de Productos Farmacéuticos [Peruvian Drug Price Observatory]. 2012. http://observatorio.digemid.minsa.gob.pe. Accessed 10 Aug 2013.

19. Banco Central de Reserva del Perú. Series Estadísticas. 2013. http://www.bcrp.gob.pe/. Accessed 15 Aug 2013.

20. World Bank. World Development Indicators. 2012. http://data.worldbank.org/ data-catalog/world-development-indicators. Accessed 23 Aug 2013. 
21. World Health Organization. Cost-Effectiveness Thresholds. http://www.who.int/ choice/costs/CER_thresholds/en/. Accessed 15 Aug 2013.

22. Stockl K, Vanderplas A, Tafesse E, Chang E. Costs of lower-extremity ulcers among patients with diabetes. Diabetes Care. 2004;27(9):2129-34.

23. Apelqvist J, Ragnarson-Tennvall G, Larsson J, Persson U. Long-term costs for foot ulcers in diabetic patients in a multidisciplinary setting. Foot Ankle Int. 1995;16(7):388-94.

24. Van Houtum WH, Lavery LA, Harkless LB. The costs of diabetes-related lower extremity amputations in the Netherlands. Diabet Med. 1995;12(9):777-81.

25. Harrington C, Zagari MJ, Corea J, Klitenic J. The management of lower-extremity diabetic ulcers. Manag Care Interface. 2000;23(9):80-7.

26. Holzer SE, Camerota A, Martens L, Cuerdon T, Crystal-Peters J, Zagari M. Costs and duration of care for lower extremity ulcers in patients with diabetes. Clin Ther. 1998;20(1):169-81.

27. Cook J, Simonson D. Epidemiology and Health Care Cost of Diabetic Foot Problems. In: Veves A, Giurini JM, LoGerfo FW, editors. The Diabetic Foot. Totowa, NJ (United States): Humana Press; 2012. p. 17-32.

28. Li R, Zhang P, Barker LE, Chowdhury FM, Zhang X. Cost-Effectiveness of Interventions to Prevent and Control Diabetes Mellitus: A Systematic Review. Diabetes Care. 2010;33(8):1872-94.

29. Boulton AJ, Armstrong DG, Albert SF, Frykberg RG, Hellman R, Kirkman MS, et al. Comprehensive foot examination and risk assessment. A report of the Task Force of the Foot Care Interest Group of the American Diabetes Association, with endorsement by the American Association of Clinical Endocrinologists. Phys Ther. 2008:88(11):1436-43.

30. Houghton VJ, Bower VM, Chant DC. Is an increase in skin temperature predictive of neuropathic foot ulceration in people with diabetes? A systematic review and meta-analysis. J Foot Ankle Res. 2013;6(1):31.

31. Ragnarson Tennvall G, Apelqvist J. Health-economic consequences of diabetic foot lesions. Clin Infect Dis. 2004;39 Suppl 2:S132-9.

32. Ragnarson Tennvall G, Apelqvist J. Prevention of diabetes-related foot ulcers and amputations: a cost-utility analysis based on Markov model simulations. Diabetologia. 2001;44(11):2077-87.

33. Ortegon MM, Redekop WK, Niessen LW. Cost-effectiveness of prevention and treatment of the diabetic foot: a Markov analysis. Diabetes Care. 2004;27(4):901-7.

34. Habacher W, Rakovac I, Görzer E, Haas W, Gfrerer RJ, Wach P, et al. A model to analyse costs and benefit of intensified diabetic foot care in Austria. J Eval Clin Pract. 2007;13(6):906-12.

35. Ollendorf DA, Kotsanos JG, Wishner WJ, Friedman M, Cooper T, Bittoni M, et al. Potential economic benefits of lower-extremity amputation prevention strategies in diabetes. Diabetes Care. 1998;21(8):1240-5.

36. Wild S, Roglic G, Green A, Sicree R, King H. Global Prevalence of Diabetes. Diabetes Care. 2004;27(5):1047-53.

\section{Submit your next manuscript to BioMed Central and take full advantage of:}

- Convenient online submission

- Thorough peer review

- No space constraints or color figure charges

- Immediate publication on acceptance

- Inclusion in PubMed, CAS, Scopus and Google Scholar

- Research which is freely available for redistribution 